\title{
Imaging the Distribution of Gastrin-Releasing Peptide Receptors in Cancer
}

\author{
Lucia Baratto ${ }^{1}$, Heying Duan ${ }^{1}$, Helmut Mäcke ${ }^{2}$, and Andrei Iagaru ${ }^{1}$ \\ ${ }^{1}$ Division of Nuclear Medicine and Molecular Imaging, Department of Radiology, Stanford University, Stanford, California; and \\ ${ }^{2}$ Department of Nuclear Medicine, University Hospital of Freiburg, Freiburg, Germany
}

\begin{abstract}
Targeting tumor-expressed receptors using selective molecules for diagnostic, therapeutic, or both diagnostic and therapeutic (theragnostic) purposes is a promising approach in oncologic applications. Such approaches have increased significantly over the past decade. Peptides such as gastrin-releasing peptide receptors targeting radiopharmaceuticals are small molecules with fast blood clearance and urinary excretion. They demonstrate good tissue diffusion, low immunogenicity, and highly selective binding to their target cell-surface receptors. They are also easily produced. Gastrin-releasing peptide receptors, part of the bombesin family, are overexpressed in many tumors, including breast and prostate cancer, and therefore represent an attractive target for future development.
\end{abstract}

Key Words: GRPR; PET; cancer; bombesin

J Nucl Med 2020; 61:792-798

DOI: 10.2967/jnumed.119.234971

\section{$\mathbf{C}$}

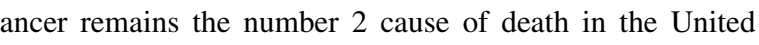
States, second only to heart disease. It is estimated that approximately 606,880 Americans will die from cancer and 1,806,590 new cancer cases will be diagnosed in the United States in 2020 (1). The receptor-mediated targeting of tumors is an area of investigation under constant development that attempts to identify a biomarker that is overexpressed on the surface of cancer cells and bind its ligand to carriers that allow tumor visualization and treatment. The success of this approach depends on the selectivity of the receptor for certain malignant cells, as well as on its binding specificity to the targeting ligand. Here, we will introduce the bombesin receptor family and focus on the gastrin-releasing peptide receptors (GRPRs), which are overexpressed in various cancers (2-8). A special emphasis will be on prostate and breast cancers, in which GRPR expression has been studied the most.

\section{BOMBESIN}

Bombesin is a 14-amino-acid peptide (Pyr-Gln-Arg-Leu-GlyAsn-Gln-Trp-Ala-Val-Gly-His-Leu-Met- $\mathrm{NH}_{2}$ ) purified for the first time in 1970 from the skin of 2 European frogs, Bombina and

Received Dec. 16, 2019; revision accepted Feb. 6, 2020.

For correspondence or reprints contact: Andrei lagaru, Division of Nuclear Medicine and Molecular Imaging, Department of Radiology, Stanford University, 300 Pasteur Dr., Stanford, CA 94305.

E-mail: aiagaru@stanford.edu

Published online Feb. 14, 2020.

COPYRIGHT (C 2020 by the Society of Nuclear Medicine and Molecular Imaging.
Bombina variegate $(9,10)$. Bombesin had a structural similarity to that of ranatensin, a peptide isolated only few months earlier from the skin of a different frog (11). In 1978, the mammalian counterpart to the amphibian bombesin was isolated from porcine nonantral gastric tissue and called gastrin-releasing polypeptide (GRP) because of its main function, gastric acid stimulation due to the release of gastrin (12). Later on, Minamino et al. identified the mammalian counterpart to the amphibian ranatensin in the porcine spinal cord, and they called it neuromedin-B (13). These 2 mammalian bombesin peptides are highly expressed in the human peripheral tissues and in the central nervous system (14). Three different receptors have been discovered for the mammalian bombesin peptides: $\mathrm{BB}_{1}$ (neuromedin-B receptor), $\mathrm{BB}_{2}$ (GRPR), and $\mathrm{BB}_{3}$ (bombesin receptor subtype 3) (15-18). These are 7transmembrane-domain, G-protein-coupled receptors. Bombesin receptor subtype 3 is an orphan receptor, which means that at present its natural ligand is unknown, but it has been included in the bombesin receptor family because of its high homology to neuromedin-B receptor and GRPR $(19,20)$. Among them, GRPR has been the most extensively studied.

\section{GRP AND GRPR NORMAL BIODISTRIBUTION AND PHYSIOLOGIC FUNCTION}

GRPRs are highly concentrated in the pancreas and expressed at lower levels in the colon, breast, prostate, and some regions of the central nervous system, including hippocampus, hypothalamus, amygdala, and pons $(21,22)$. The first human atlas of the physiologic uptake of a GRPR antagonist radiolabeled with ${ }^{68} \mathrm{Ga}$ has been recently published by our group: the highest uptake was seen in the pancreas, followed by clearance in the urinary system; mild to moderate uptake was seen in the gastrointestinal tract (23).

GRP binds with very high affinity to GRPR, which mediates various physiologic mechanism in the human body: it controls gastrointestinal motility and gastric emptying, inducing smooth muscle contraction (24); it causes the release of endogenous gastrin by activating sensory neurons in the gastric mucosa $(25,26)$; it regulates the release of pancreatic enzymes (27); and it has a role in the immunologic responses $(28,29)$ and in several brain functions such as regulation of circadian rhythm $(30,31)$, memory (32), stress, fear, and anxiety (33-35).

\section{GRP AND GRPR EXPRESSION IN VARIOUS CANCERS}

GRP and GRPR expression and mechanisms of action have been widely studied both in vitro and in vivo for many different tumor types. Most of the studies have described GRPR acting as an autocrine growth factor receptor in tumor cells, increasing their ability to proliferate. Another hypothesis is that GRP and GRPR 
would act as a morphogen factor able to retain the tumor in a better-differentiated state. This has been evaluated in colon cancer in vivo xenograft studies, in which moderately differentiated tumors became better differentiated in mice expressing GRP and GRPR but progressively degenerated into poorly differentiated tumors in GRP- and GRPR-negative mice (36).

GRPR expression is higher in prostate cancer than in normal prostate tissue, but variable expression can be found in benign prostate hyperplasia $(6,37,38)$, and the degree to which this may confound image interpretation, creating false-positive findings, is still under investigation. Several groups evaluated the correlation between GRPR expression and clinical features of prostate cancer such as Gleason score, stage of disease, and prostate-specific antigen (PSA) levels (38-42). The results are not definitive, and prospective trials should be performed to evaluate the relationship between GRPR expression and stage of disease, and in androgennaive versus castration-resistant patients, to better select cases in which the use of this molecular target is appropriate.

GRPR overexpression in breast cancer has been extensively demonstrated (7,43-49), particularly in estrogen receptor (ER)expressing tumors (50-52). A recent study analyzed and compared ${ }^{68}$ Ga-RM2 (DOTA-4-amino-1-carboxymethyl-piperidine-D-Phe-GlnTrp-Ala-Val-Gly-His-Sta-Leu- $\mathrm{NH}_{2}$ ) and ${ }^{18} \mathrm{~F}-\mathrm{FDG}-$ specific binding in tumoral areas of 14 breast cancer samples using tissue microimaging. Immunohistochemistry for ER, progesterone receptor (PR), Ki-67, human epidermal growth factor receptor type 2, and GRPR was also assessed in all specimens (50). The authors found a significantly higher specific binding of ${ }^{68} \mathrm{Ga}-\mathrm{RM} 2$ in the ER- and PR-positive groups than in ER- and PR-negative tumors; ${ }^{68} \mathrm{Ga}-\mathrm{RM} 2$ binding was higher in the low-Ki-67 group, whereas no difference was associated with human epidermal growth factor receptor type 2 status. ${ }^{18} \mathrm{~F}$-FDG uptake was lower in ER-positive than in ER-negative cancers; it looked similar in PR groups and higher in the high Ki-67 group, and no differences were associated with human epidermal growth factor receptor type 2 status. ${ }^{68} \mathrm{Ga}-$ RM2 binding was significantly higher in tumors without ${ }^{18} \mathrm{~F}-\mathrm{FDG}$ uptake. These results suggest that ${ }^{68} \mathrm{Ga}-\mathrm{RM} 2 \mathrm{PET}$ may be complementary to ${ }^{18} \mathrm{~F}$-FDG PET in ER-positive tumors with a low proliferation index.

Mattei et al. analyzed 238 lung cancer specimens, including both small and non-small cell lung cancer, and correlated the immunohistochemistry results with clinical stage, cell type, sex, and survival (53). GRPR expression was more abundant in advanced-stage disease, and a significant correlation was found between higher clinical stage and more intense GRPR expression. The overall GRPR expression between small cell lung cancer and non-small cell lung cancer was similar, but the intensity of the expression was higher in non-small cell lung cancer.

\section{NOTEWORTHY}

- GRPRs, part of the bombesin family, are overexpressed in many malignancies, including breast and prostate cancer, and therefore represent an attractive target for future development.

- Peptides such as GRPR-targeting radiopharmaceuticals are small molecules with fast blood clearance and urinary excretion.

- Both diagnostic and therapeutic versions have been developed and are currently in clinical trials.
An immunohistochemistry study was performed by Carroll et al. on 50 human colon cancer specimens (54). Both GRP and GRPR were highly expressed in most cancers $(62 \%)$, whereas no expression was detected in normal adjacent tissues. An interesting finding was that coexpression of the 2 proteins was seen always in well-differentiated tumors regions but was never observed in poorly differentiated tumor areas, suggesting a strong relation between GRP/GRPR expression and tumor differentiation.

A large number of other tumors overexpress GRPR on their cell surface, including head and neck cancer, renal cancer, and intestinal and bronchial carcinoids $(43,55)$; however, aside from breast and prostate cancer, only few clinical studies are currently under way.

\section{CLINICAL EVALUATION OF GRP AND GRPR IN PROSTATE CANCER}

\section{Diagnostic Studies}

The use of GRP analogs in prostate cancer patients has increased recently. Various bombesin analogs have been labeled with different radioisotopes $\left({ }^{64} \mathrm{Cu},{ }^{18} \mathrm{~F},{ }^{68} \mathrm{Ga}\right)$. GRPR antagonists replaced agonists because of their more favorable pharmacokinetics; they block the receptor instead of activating it (as agonists do), resulting in no gastrointestinal side effects and increased binding $(56,57)$.

Roivainen et al. reported the first-in-humans study of ${ }^{68} \mathrm{Ga}-\mathrm{RM} 2$ (58). Five healthy volunteers were included. The radiopharmaceutical was rapidly excreted via the urinary system and accumulated predominantly in the pancreas; acceptable radiation exposure (effective dose of $7.7 \mathrm{mSv}$ for an injected dose of $150 \mathrm{MBq}$ ) was reported, with the urinary bladder wall and the pancreas being the organs with the highest absorbed doses $(0.61$ and $0.51 \mathrm{mSv} / \mathrm{MBq}$, respectively). Similar results were reported for 2 other radiopharmaceuticals: ${ }^{68} \mathrm{Ga}$-RM26 $\left({ }^{68} \mathrm{Ga}-1,4,7\right.$-triazacyclononane$N, N^{\prime}, N^{\prime \prime}$-triaceticacid-D-Phe-Gln-Trp-Ala-Val-Gly-His-Sta-Leu- $\mathrm{NH}_{2}$ ) and ${ }^{68} \mathrm{Ga}-\mathrm{NODAGA}-\mathrm{MJ} 9$ ( ${ }^{68} \mathrm{Ga}-\mathrm{NODAGA}-4$-amino-1-carboxymethyl-piperidine-D-Phe-Gln-Trp-Ala-Val-Gly-His-Sta-Leu- $\mathrm{NH}_{2}$ ) $(59,60)$.

Kahkönen et al. analyzed 11 patients with prostate cancer who underwent ${ }^{68} \mathrm{Ga}$-RM2 PET/CT before surgery (61). The regionbased PET accuracy across all patients was $83 \%$, with a sensitivity and specificity of $89 \%$ and $81 \%$, respectively. The authors reported a significantly higher $\mathrm{SUV}_{\max }$ in tumor foci than in benign prostate hyperplasia and normal prostate tissue. Similar results were recently reported by Touijer et al. (41). Immunohistochemistry was performed to look for both GRPR and prostate-specific membrane antigen (PSMA) expression, since the latter is currently the target of the most used (but not yet Food and Drug Administration-approved in the United States) radiopharmaceuticals in the evaluation of prostate cancer. Immunohistochemistry showed no correlation between GRPR and PSMA expression, suggesting that they may provide complementary information. Fassbender et al. analyzed 15 patients with biopsy-proven prostate cancer and compared the PET scan performed before surgery with the histopathology results (62). Although $93 \%$ of the patients had at least 1 focus of pathologic ${ }^{68} \mathrm{Ga}-\mathrm{RM} 2$ uptake, the overall PET accuracy using the region-based visualization was rather low (63\% across all patients). No significant correlations were found between region-based $\mathrm{SUV}_{\max }$ and histopathology or between whole-prostate 
$\mathrm{SUV}_{\text {max }}$ and postoperative $\mathrm{T}$ category or International Society of Urological Pathology score.

Unpublished data from our group indicate a high detection rate of newly diagnosed prostate cancer using ${ }^{68} \mathrm{Ga}-\mathrm{RM} 2$ PET in 34 patients who underwent either surgery $(n=27)$ or radiotherapy $(n=7)$ after imaging. ${ }^{68} \mathrm{Ga}$-RM2 PET/CT showed intraprostatic cancer lesions in 33 patients ( 1 patient had a negative scan), which correlated with pathology in 27 patients who underwent prostatectomy. Increased uptake was identified in 4 pelvic lymph nodes, confirmed by pathology $(n=3)$ or follow-up imaging $(n=1)$. An example is shown in Figure 1.

${ }^{68} \mathrm{Ga}-\mathrm{RM} 2$ was evaluated more extensively at biochemical recurrence of prostate cancer. Our group published preliminary results from 32 prostate cancer patients who underwent ${ }^{68} \mathrm{Ga}$ RM2 PET/MRI at biochemical recurrence with negative conventional imaging (63). ${ }^{68} \mathrm{Ga}-\mathrm{RM} 2 \mathrm{PET}$ and MRI identified recurrent disease in 23 and 11 of these patients, respectively. PET was positive for all 11 patients with MRI pathologic findings. Our unpublished data from 114 participants enrolled to date indicate the following trend of ${ }^{68} \mathrm{Ga}-\mathrm{RM} 2$ PET positivity: $31.8 \%$ for a PSA level of less than $0.5 \mathrm{ng} / \mathrm{dL}(n=22), 60 \%$ for a PSA level of $0.5-1.0 \mathrm{ng} / \mathrm{dL}(n=15), 64.7 \%$ for a PSA level of $1.0-2.0 \mathrm{ng} / \mathrm{dL}(n=17), 81.8 \%$ for a PSA level of $2.0-$ $5.0 \mathrm{ng} / \mathrm{dL}(n=22)$, and $87.2 \%$ for a PSA level of more than 5.0 $\mathrm{ng} / \mathrm{dL}(n=38)(64)$. An example is shown in Figure 2. Another study compared ${ }^{68} \mathrm{Ga}$-RM2 with ${ }^{18} \mathrm{~F}$-fluoroethylcholine PET/ $\mathrm{CT}$ in patients with biochemically recurrent PC (65). The authors retrospectively analyzed 16 men with biochemical relapse and negative or inconclusive ${ }^{18} \mathrm{~F}$-fluoroethylcholine PET/CT results. Overall, ${ }^{68} \mathrm{Ga}-\mathrm{RM} 2 \mathrm{PET} / \mathrm{CT}$ showed abnormal uptake in 10 of 16 patients $(63 \%)$ : for 2 patients with inconclusive results on ${ }^{18} \mathrm{~F}$-fluoroethylcholine PET/CT, ${ }^{68} \mathrm{Ga}-\mathrm{RM} 2$ showed additional lymph nodes in the pelvis and multiple bone lesions. However, because the median PSA at the time of ${ }^{18} \mathrm{~F}$-fluoroethylcholine PET/CT was lower than that at the time of ${ }^{68} \mathrm{Ga}$ -

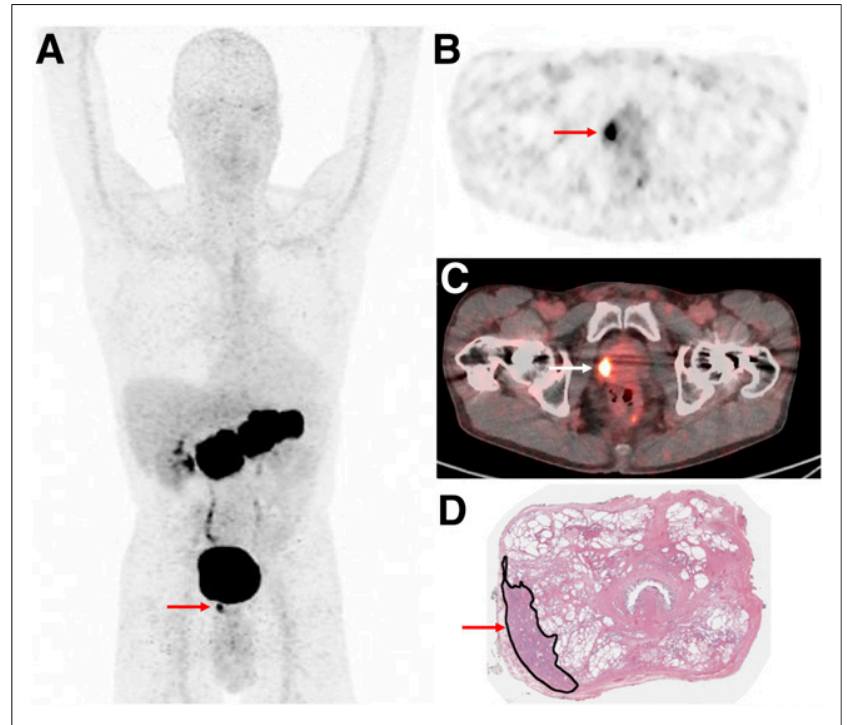

FIGURE 1. A 64-y-old man with newly diagnosed high-risk prostate cancer (PSA, $6.42 \mathrm{ng} / \mathrm{mL}$ ). Intense focal ${ }^{6} \mathrm{Ga}-\mathrm{RM} 2$ uptake is seen in prostate gland (arrows) on maximum-intensity-projection (A), axial PET (B), and PET/CT (C) images, correlating with location of cancer marked in black ink on postprostatectomy histopathology slide (D).

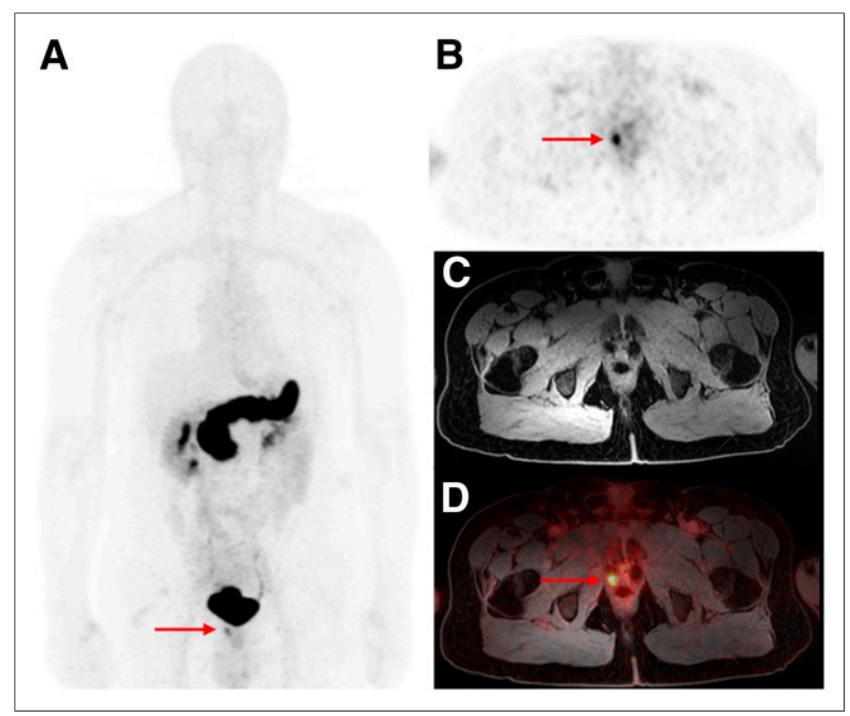

FIGURE 2. A 72-y-old man with $B C R$ prostate cancer (PSA, $0.72 \mathrm{ng} / \mathrm{mL}$ ). $(A, B$, and $D)$ Intense ${ }^{68} \mathrm{Ga}-\mathrm{RM} 2$ uptake is seen in right prostate bed (arrows) on early maximum-intensity-projection (A), axial PET (B), and PET/MR (D) images. (C) Corresponding axial T1-weighted MR image is also shown.

RM2 PET/CT (2.4 vs. $5.5 \mathrm{ng} / \mathrm{mL}$, respectively), further investigation in larger prospective clinical trials is needed to confirm these data.

${ }^{68} \mathrm{Ga}$ was used to label other GRPR-targeting peptides. The DOTA-conjugated GRPR antagonist SB3 (DOTA-paminomethylaniline-diglycolic acid-D-Phe-Gln-Trp-Ala-Val-Gly-His-Leu-NHEt) was tested on 17 patients with breast or prostate cancer (66). All patients had disseminated disease, and many had previous treatments, including hormonal therapies; a positive scan was registered in about $50 \%$ of cases. Data suggest that GRPR expression declines in advanced androgen-independent stages of prostate cancer, especially in osseous metastases $(6,38)$. An optimized version, ${ }^{68} \mathrm{Ga}-\mathrm{NeoBOMB} 1$, was developed by replacement of the C-terminal $\mathrm{Leu}^{13}-\mathrm{Met}^{14}-\mathrm{NH}_{2}$ dipeptide of SB3 with $\mathrm{Sta}^{13}-\mathrm{Leu}^{14}-\mathrm{NH}_{2}$ (67). At 30 min after injection, more than $90 \%$ of ${ }^{67} \mathrm{Ga}-\mathrm{NeoBOMB} 1$ and $80 \%$ of ${ }^{177} \mathrm{Lu}-\mathrm{NeoBOMB} 1$ were found still intact in peripheral mouse blood, a characteristic that was pointed out by the authors as it makes an argument for use as theragnostic agents.

${ }^{68} \mathrm{Ga}-\mathrm{RM} 26$ is another GRPR antagonist with high affinity to GRP (59). The first-in-humans study included 28 patients with prostate cancer (17 newly diagnosed and 11 after therapy). ${ }^{68} \mathrm{Ga}-\mathrm{RM} 26 \mathrm{PET} / \mathrm{CT}$ was positive in 15 of 17 patients at the initial diagnosis of PC $(88.2 \%)$ and in 11 of 11 with biochemical recurrence. Twenty-two patients also underwent ${ }^{68} \mathrm{Ga}$-bombesin PET/CT, a GRPR agonist radiopharmaceutical. ${ }^{68} \mathrm{Ga}-\mathrm{RM} 26 \mathrm{de}-$ tected more primary tumors, lymph nodes, and bone metastases than did ${ }^{68} \mathrm{Ga}$-bombesin, further confirming the improved performance of antagonists over agonists.

${ }^{64} \mathrm{Cu}$ - and ${ }^{18} \mathrm{~F}$-labeled GRPR antagonists were also evaluated in small cohorts of prostate cancer patients. ${ }^{64} \mathrm{Cu}-\mathrm{CB}-\mathrm{TE} 2 \mathrm{~A}-\mathrm{AR} 06$ ( ${ }^{64} \mathrm{Cu}$-4,11-bis(carboxymethyl)-1,4,8,11-tetraazabicyclo(6.6.2)hexadecane)PEG $_{4}$-D-Phe-Gln-Trp-Ala-Val-Gly-His-Sta-LeuNH ${ }_{2}$ ) was assessed in 4 patients with newly diagnosed prostate cancer (68); favorable tumor uptake and image contrast were reported for the radiotracer. The longer half-life of ${ }^{64} \mathrm{Cu}$ will allow for dosimetry applications before therapy using a GRPR antagonist. ${ }^{18}$ F-BAY 864367 
(3-cyano-4- ${ }^{18} \mathrm{~F}$-fluorobenzoyl-Ala $\left(\mathrm{SO}_{3} \mathrm{H}\right)$-Ala $\left(\mathrm{SO}_{3} \mathrm{H}\right)$-Ava-Gln-TrpAla-Val- $N$-MeGly-His-Sta-Leu- $\mathrm{NH}_{2}$ ) was used in a first-in-humans study evaluating 10 patients with primary prostate cancer $(n=5)$ or recurrent disease $(n=5)(69) .{ }^{18} \mathrm{~F}-\mathrm{BAY} 864367$ PET/CT was compared with ${ }^{18} \mathrm{~F}$-fluorocholine PET/CT and with histopathology when available. Among patients with primary prostate cancer ${ }^{18} \mathrm{~F}-\mathrm{BAY}$ 864367 PET/CT detected 3 of 5 lesions; for the 2 negative scans, both ${ }^{18} \mathrm{~F}$-fluorocholine PET/CT and histopathology confirmed the prostate lesions. Only 2 recurrent-disease lesions were detected by ${ }^{18} \mathrm{~F}$-BAY 864367, whereas ${ }^{18} \mathrm{~F}$-fluorocholine PET/CT identified suggestive lesions in all 5 patients.

\section{Theragnostic Studies}

The first-in-humans dosimetry study of a ${ }^{177} \mathrm{Lu}$-labeled GRPR antagonist was published by Kurth et al. (70). Four patients with metastatic castration-resistant prostate cancer received a mean dose of $4.48 \mathrm{GBq}$ of ${ }^{177} \mathrm{Lu}-\mathrm{RM} 2$. The most intense physiologic uptake was seen in the pancreas, as expected from diagnostic studies (mean absorbed dose, $4.5 \pm 1.6 \mathrm{~Gy}$ ), but not so high as to prevent further administrations (71). For the bone marrow, the reported absorbed dose of ${ }^{177} \mathrm{Lu}-\mathrm{RM} 2$ was low and similar to what was previously described for PSMA ligand therapies $(72,73)$, whereas for the kidneys the ${ }^{177} \mathrm{Lu}-\mathrm{RM} 2$ mean absorbed dose was lower than that for ${ }^{177} \mathrm{Lu}$-PSMA-617 (72) or ${ }^{177} \mathrm{Lu}$-DOTATATE (74). Bone metastases had the highest uptake, followed by lymph nodes and soft-tissue lesions. This study confirmed a high interpatient variability in terms of tumor uptake, a characteristic that had already been described (62) and implies that differences in tumor biology affect GRPR expression. Although these preliminary results are encouraging, further evaluations are needed.

Radiopharmaceuticals targeting GRPR are promising tracers for prostate cancer evaluation, showing a high detection rate for local and locoregional disease; they are accurate for the assessment of metastatic foci as well, although further evaluation is needed to understand the relation between GRPR expression and advanced hormone-resistant prostatic tumors. Compared with PSMA, whose high sensitivity and specificity in prostate cancer patients have been widely demonstrated (75-83), GRPR could play an important complementary role for PSMA-negative cancer and for tumors characterized by a heterogeneity of receptors expressed on their cell surface.

\section{CLINICAL EVALUATION OF GRP AND GRPR IN BREAST CANCER}

Although only a few pilot translational studies evaluating GRPR expression in breast cancer patients have been published so far, preliminary results seem to confirm what in vitro data already suggested: GRPR expression is strongly present in ER-positive tumors; furthermore, when the primary tumor is GRPR-positive, the lymph node metastases also show GRPR overexpression $(51,52,66)$.

Stoykow et al. evaluated the performance of ${ }^{68} \mathrm{Ga}-\mathrm{RM} 2 \mathrm{PET} /$ CT in 15 patients with newly diagnosed breast cancer (84). Eighteen breast cancer lesions were known from core-needle biopsy ( 3 patients had bilateral lesions). ${ }^{68} \mathrm{Ga}-\mathrm{RM} 2 \mathrm{PET} / \mathrm{CT}$ clearly detected 13 of these 18 lesions; the 5 PET false-negative results were tumors with an uptake level not distinguishable from normal breast tissue. However, in these cases, metastatic axillary lymph nodes were identified. All cancers seen on PET showed positivity for ER and PR expression; among the 5 cancers not detected by PET, only 1 was ER-positive, with an immunohistochemical ER expression of $30 \%$. In the multivariate analysis, ER status was the primary predictor of ${ }^{68} \mathrm{Ga}-\mathrm{RM} 2$ uptake.
Another group studied breast cancer patients using ${ }^{68} \mathrm{Ga}-\mathrm{RM} 26$ PET/CT (85), which detected 29 tumors of 34 confirmed by histopathology. The 5 PET-negative tumors had un uptake that was lower than or equal to uptake by normal breast tissue. PET positivity correlated with ER status: 26 of 28 ER-positive primary cancers were also PET-positive. Histopathology confirmed the presence of lymph node metastases in 18 patients; PET was positive in lymph nodes for 15 of them. ${ }^{68} \mathrm{Ga}$-RM26 PET/CT missed metastases in 3 lymph nodes that were $1 \mathrm{~mm}$ in size. The $\mathrm{SUV}_{\max }$ was significantly higher in ER-positive tumors than in ER-negative tumors and positively correlated with the expression level of GRPR. Uptake level was associated with menstrual cycle in both normal breast tissue and cancer $\left(\mathrm{SUV}_{\max }\right.$ was significantly higher during the secretory phase than in either the nonsecretory phase or the postmenopause phase); 4 of 5 PET-negative scans were performed on women during their secretory phase. The sensitivity, specificity, and accuracy of ${ }^{68} \mathrm{Ga}-\mathrm{RM} 26$ PET/CT increased either when ER-negative tumors were not considered or when patients who underwent the scan during their secretory phase were removed from the analysis.

An example from our own experience with ${ }^{68} \mathrm{Ga}-\mathrm{RM} 2 \mathrm{PET} /$ MRI in ER-positive breast cancer is shown in Figure 3. Supplemental Tables 1 and 2 summarize the clinical studies in prostate and breast cancer (supplemental materials are available at http://jnm. snmjournals.org).

\section{FUTURE DIRECTIONS}

One area of development is to explore and understand the variability in GRPR expression in prostate cancer tumors in order to select the optimal imaging and therapy strategy for each patient. For tumors expressing GRPR, the detection rates for both the primary lesions and metastases are high. The well-known concept of intratumor heterogeneity (i.e., types of receptors expressed, receptor expression level, grade of malignancy, resistance to therapy) led to the development of bivalent prostate cancer-targeting peptides with the ability to target 2 receptors. In particular, heterodimers targeting both PSMA and GRPR have been evaluated $(86,87)$. In addition, strategies to decrease physiologic uptake

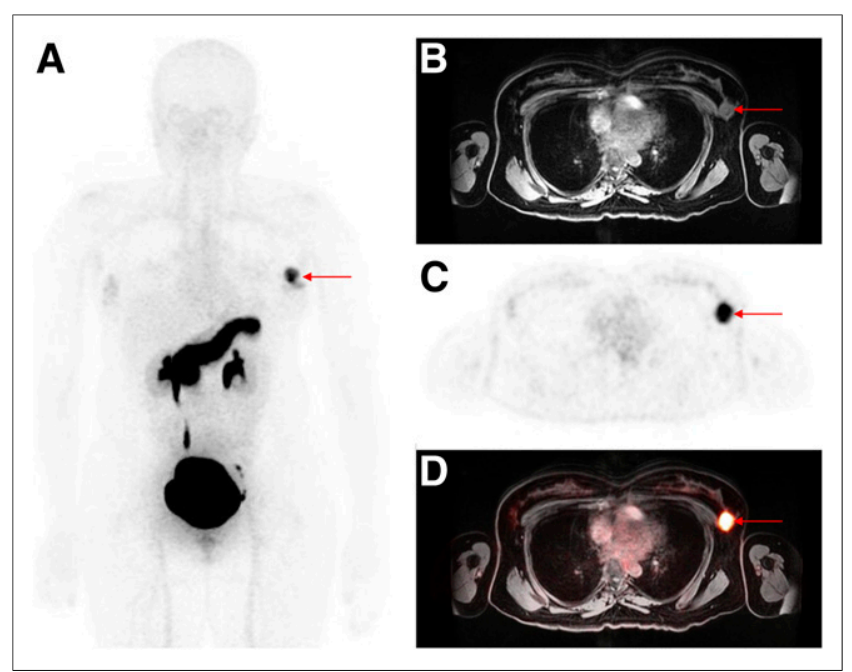

FIGURE 3. A 36-y-old woman with newly diagnosed ER-positive breast cancer. Intense ${ }^{68} \mathrm{Ga}-\mathrm{RM} 2$ uptake is seen in left breast (arrows) on maximum-intensity-projection (A), axial T1-weighted MR (B), axial PET (C), and PET/MR (D) images. 


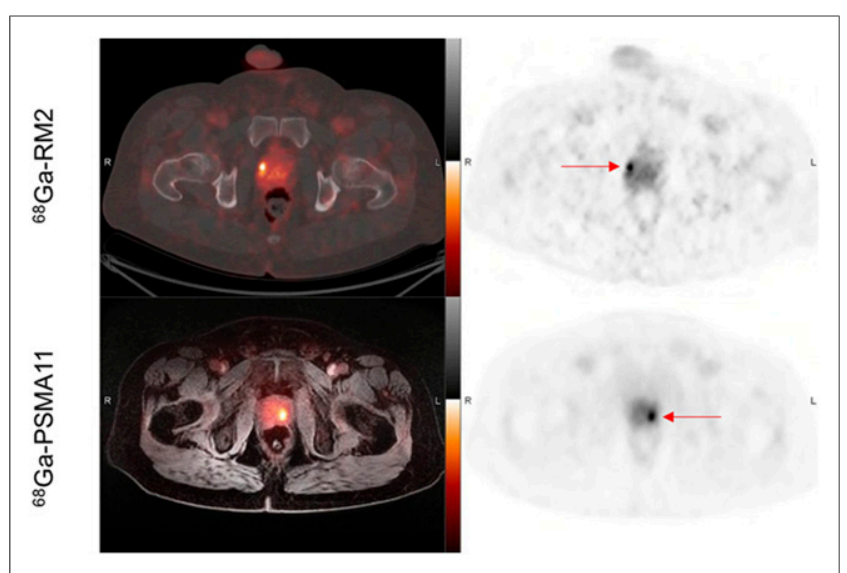

FIGURE 4. A 54-y-old man with newly diagnosed intermediaterisk prostate cancer (PSA, $5.09 \mathrm{ng} / \mathrm{mL}$ ). Focal ${ }^{68} \mathrm{Ga}-\mathrm{RM} 2$ uptake is seen in right prostate gland (arrow) on axial fused PET/CT and PET images (top row), whereas focal ${ }^{68} \mathrm{Ga}-\mathrm{PSMA} 11$ uptake is seen in left prostate gland (arrow) on axial PET/MR and PET images (bottom row). Both were prostate cancer on postprostatectomy histopathology.

in the pancreas and to increase tumor uptake are being evaluated by various groups.

Another avenue for future use of GRPR antagonists is novel indications both in prostate cancer (biopsy guidance, evaluation or response to targeted local therapy) and in other cancers such as gastrointestinal and gynecologic malignancies. Although PSMA imaging and therapy are gaining significant traction at various stages of prostate cancer, GRPR antagonists are likely to play a complementary role. An example of ${ }^{68} \mathrm{Ga}-\mathrm{RM} 2$ and ${ }^{68} \mathrm{Ga}$-PSMA11 PET in the same patient showing 2 different primary prostate cancer lesions is presented in Figure 4.

Lastly, it seems clear that GRPR expression in breast cancer cells strongly correlates with ER-positive tumors. This correlation opens opportunities to expand the use of GRPR antagonists not only for diagnostic purposes but also for therapeutic purposes in this patient population.

\section{CONCLUSION}

Cancer imaging and therapy using peptide-based radiopharmaceuticals have ushered in a new era for nuclear medicine. Radiolabeled bombesin analogs are promising theragnostic agents for GRPR-expressing tumors, being able to detect primary tumors and metastatic lesions with high sensitivity and specificity. Larger prospective clinical trials are needed to improve understanding of the relation between the GRPR expression and biologic behavior of different cancer cells, in order to better select patients who will benefit from their use.

\section{DISCLOSURE}

No potential conflict of interest relevant to this article was reported.

\section{REFERENCES}

1. Siegel RL, Miller KD, Jemal A. Cancer statistics, 2020. CA Cancer J Clin. 2020;70:7-30

2. Sun B, Schally AV, Halmos G. The presence of receptors for bombesin/GRP and mRNA for three receptor subtypes in human ovarian epithelial cancers. Regul Pept. 2000;90:77-84.
3. Ehlers RA, Kim S, Zhang Y, et al. Gut peptide receptor expression in human pancreatic cancers. Ann Surg. 2000;231:838-848.

4. Preston SR, Woodhouse LF, Jones-Blackett S, Miller GV, Primrose JN. Highaffinity binding sites for gastrin-releasing peptide on human colorectal cancer tissue but not uninvolved mucosa. Br J Cancer. 1995;71:1087-1089.

5. Uchida K, Kojima A, Morokawa N, et al. Expression of progastrin-releasing peptide and gastrin-releasing peptide receptor mRNA transcripts in tumor cells of patients with small cell lung cancer. J Cancer Res Clin Oncol. 2002;128:633640.

6. Markwalder R, Reubi JC. Gastrin-releasing peptide receptors in the human prostate: relation to neoplastic transformation. Cancer Res. 1999;59:1152-1159.

7. Gugger M, Reubi JC. Gastrin-releasing peptide receptors in non-neoplastic and neoplastic human breast. Am J Pathol. 1999;155:2067-2076.

8. Fleischmann A, Reubi JC. Overexpression of gastrin-releasing peptide receptors in tumor-associated blood vessels of human ovarian neoplasms. Cell Oncol. 2007; 29:421-433.

9. Anastasi A, Erspamer V, Bucci M. Isolation and structure of bombesin and alytesin, 2 analogous active peptides from the skin of the European amphibians Bombina and Alytes. Experientia. 1971;27:166-167.

10. Erspamer V, Erpamer GF, Inselvini M. Some pharmacological actions of alytesin and bombesin. J Pharm Pharmacol. 1970;22:875-876.

11. Nakajima TT, Pisano JJ. Isolation and structure of a new vasoactive polypeptide. Fed Proc. 1970;29:282.

12. McDonald TJ, Nilsson G, Vagne M, Ghatei M, Bloom SR, Mutt V. A gastrin releasing peptide from the porcine nonantral gastric tissue. Gut. 1978;19:767774.

13. Minamino N, Kangawa K, Matsuo H. Neuromedin B: a novel bombesin-like peptide identified in porcine spinal cord. Biochem Biophys Res Commun. 1983;114: 541-548.

14. Jensen RT, Battey JF, Spindel ER, Benya RV. International Union of Pharmacology. LXVIII. Mammalian bombesin receptors: nomenclature, distribution, pharmacology, signaling, and functions in normal and disease states. Pharmacol Rev. 2008;60:1-42.

15. Jensen RT, Moody T, Pert C, Rivier JE, Gardner JD. Interaction of bombesin and litorin with specific membrane receptors on pancreatic acinar cells. Proc Natl Acad Sci USA. 1978;75:6139-6143.

16. Moody TW, Pert CB, Rivier J, Brown MR. Bomebesin: specific binding to rat brain membranes. Proc Natl Acad Sci USA. 1978;75:5372-5376.

17. Jensen RT, Gardner JD. Identification and characterization of receptors for secretagogues on pancreatic acinar cells. Fed Proc. 1981;40:2486-2496.

18. Ladenheim EE, Jensen RT, Mantey SA, McHugh PR, Moran TH. Receptor heterogeneity for bombesin-like peptides in the rat central nervous system. Brain Res. 1990;537:233-240.

19. Ramos-Álvarez I, Moreno P, Mantey SA, et al. Insights into bombesin receptors and ligands: highlighting recent advances. Peptides. 2015;72:128-144.

20. González N, Moreno P, Jensen RT. Bombesin receptor subtype 3 as a potential target for obesity and diabetes. Expert Opin Ther Targets. 2015;19:1153-1170.

21. Sano H, Feighner SD, Hreniuk DL, et al. Characterization of the bombesin-like peptide receptor family in primates. Genomics. 2004;84:139-146.

22. Xiao D, Wang J, Hampton LL, Weber HC. The human gastrin-releasing peptide receptor gene structure, its tissue expression and promoter. Gene. 2001;264:95103 .

23. Baratto L, Duan H, Laudicella R, et al. Physiological ${ }^{68} \mathrm{Ga}-\mathrm{RM} 2$ uptake in patients with biochemically recurrent prostate cancer: an atlas of semi-quantitative measurements. Eur J Nucl Med Mol Imaging. 2020;47:115-122.

24. Degen LP, Peng F, Collet A, et al. Blockade of GRP receptors inhibits gastric emptying and gallbladder contraction but accelerates small intestinal transit. Gastroenterology. 2001;120:361-368.

25. Schubert ML, Hightower J, Coy DH, Makhlouf GM. Regulation of acid secretion by bombesin/GRP neurons of the gastric fundus. Am J Physiol. 1991;260:G156G160.

26. Hildebrand P, Lehmann FS, Ketterer S, et al. Regulation of gastric function by endogenous gastrin releasing peptide in humans: studies with a specific gastrin releasing peptide receptor antagonist. Gut. 2001;49:23-28.

27. Pettersson M, Ahren B. Gastrin releasing peptide (GRP): effects on basal and stimulated insulin and glucagon secretion in the mouse. Peptides. 1987;8:55-60.

28. De la Fuente M, Del Rio M, Ferrandez MD, Hernanz A. Modulation of phagocytic function in murine peritoneal macrophages by bombesin, gastrin-releasing peptide and neuromedin C. Immunology. 1991;73:205-211.

29. Del Rio M, De la Fuente M. Chemoattractant capacity of bombesin, gastrinreleasing peptide and neuromedin $\mathrm{C}$ is mediated through PKC activation in murine peritoneal leukocytes. Regul Pept. 1994;49:185-193.

30. Levine AS, Morley JE. Stress-induced eating in rats. Am J Physiol. 1981;241: R72-R76. 
31. Kraly FS, Miller LA, Gibbs J. Diurnal variation for inhibition of eating by bombesin in the rat. Physiol Behav. 1983;31:395-399.

32. Roesler R, Luft T, Oliveira SH, et al. Molecular mechanisms mediating gastrinreleasing peptide receptor modulation of memory consolidation in the hippocampus. Neuropharmacology. 2006;51:350-357.

33. Merali Z, McIntosh J, Kent P, Michaud D, Anisman H. Aversive and appetitive events evoke the release of corticotropin-releasing hormone and bombesin-like peptides at the central nucleus of the amygdala. J Neurosci. 1998;18:4758-4766.

34. Brown MR, Gray TS. Peptide injections into the amygdala of conscious rats: effects on blood pressure, heart rate and plasma catecholamines. Regul Pept. 1988;21:95-106.

35. Shumyatsky GP, Tsvetkov E, Malleret G, et al. Identification of a signaling network in lateral nucleus of amygdala important for inhibiting memory specifically related to learned fear. Cell. 2002;111:905-918.

36. Carroll RE, Matkowskyj KA, Tretiakova MS, Battey JF, Benya RV. Gastrinreleasing peptide is a mitogen and a morphogen in murine colon cancer. Cell Growth Differ. 2000;11:385-393.

37. Sun B, Halmos G, Schally AV, Wang X, Martinez M. Presence of receptors for bombesin/gastrin-releasing peptide and mRNA for three receptor subtypes in human prostate cancers. Prostate. 2000;42:295-303.

38. Beer M, Montani M, Gerhardt J, et al. Profiling gastrin-releasing peptide receptor in prostate tissues: clinical implications and molecular correlates. Prostate. 2012; 72:318-325.

39. Nagasaki S, Nakamura Y, Maekawa T, et al. Immunohistochemical analysis of gastrin-releasing peptide receptor (GRPR) and possible regulation by estrogen receptor betacx in human prostate carcinoma. Neoplasma. 2012;59:224-232.

40. Constantinides C, Lazaris AC, Haritopoulos KN, Pantazopoulos D, Chrisofos M, Giannopoulos A. Immunohistochemical detection of gastrin releasing peptide in patients with prostate cancer. World J Urol. 2003;21:183-187.

41. Touijer KA, Michaud L, Alvarez HAV, et al. Prospective study of the radiolabeled GRPR antagonist BAY86-7548 for positron emission tomography/computed tomography imaging of newly diagnosed prostate cancer. Eur Urol Oncol. 2019; 2:166-173.

42. Schollhammer R, De Clermont Gallerande H, Yacoub M, et al. Comparison of the radiolabeled PSMA-inhibitor ${ }^{111}$ In-PSMA-617 and the radiolabeled GRP-R antagonist ${ }^{111}$ In-RM2 in primary prostate cancer samples. EJNMMI Res. 2019;9:52.

43. Reubi JC, Wenger S, Schmuckli-Maurer J, Schaer JC, Gugger M. Bombesin receptor subtypes in human cancers: detection with the universal radioligand ${ }^{125} \mathrm{I}-\left[\mathrm{D}-\mathrm{TYR}^{6}\right.$, beta-ALA $\left.{ }^{11}, \mathrm{PHE}^{13}, \mathrm{NLE}^{14}\right]$ bombesin ${ }^{6-14}$. Clin Cancer Res. 2002;8:1139-1146.

44. Reubi C, Gugger M, Waser B. Co-expressed peptide receptors in breast cancer as a molecular basis for in vivo multireceptor tumour targeting. Eur J Nucl Med Mol Imaging. 2002;29:855-862.

45. Dalm SU, Martens JW, Sieuwerts AM, et al. In vitro and in vivo application of radiolabeled gastrin-releasing peptide receptor ligands in breast cancer. $J \mathrm{Nucl}$ Med. 2015;56:752-757.

46. Bold RJ, Ishizuka J, Yao CZ, Townsend CM Jr, Thompson JC. Bombesin stimulates in vitro growth of human breast cancer independent of estrogen receptors status. Anticancer Res. 1998;18:4051-4056.

47. Miyazaki M, Lamharzi N, Schally AV, et al. Inhibition of growth of MDA-MB-231 human breast cancer xenografts in nude mice by bombesin/gastrin-releasing peptide (GRP) antagonists RC-3940-II and RC-3095. Eur J Cancer. 1998;34:710-717.

48. Nelson J, Donnelly M, Walker B, Gray J, Shaw C, Murphy RF. Bombesin stimulates proliferation of human breast cancer cells in culture. Br J Cancer. 1991; 63:933-936.

49. Yano T, Pinski J, Groot K, Schally AV. Stimulation by bombesin and inhibition by bombesin/gastrin-releasing peptide antagonist RC-3095 of growth of human breast cancer cell lines. Cancer Res. 1992;52:4545-4547.

50. Morgat C, Schollhammer R, Macgrogan G, et al. Comparison of the binding of the gastrin-releasing peptide receptor (GRP-R) antagonist ${ }^{68} \mathrm{Ga}-\mathrm{RM} 2$ and ${ }^{18} \mathrm{~F}-$ FDG in breast cancer samples. PLoS One. 2019;14:e0210905.

51. Morgat C, MacGrogan G, Brouste V, et al. Expression of gastrin-releasing peptide receptor in breast cancer and its association with pathologic, biologic, and clinical parameters: a study of 1,432 primary tumors. J Nucl Med. 2017;58:1401-1407.

52. Dalm SU, Sieuwerts AM, Look MP, et al. Clinical relevance of targeting the gastrinreleasing peptide receptor, somatostatin receptor 2, or chemokine C-X-C motif receptor 4 in breast cancer for imaging and therapy. J Nucl Med. 2015;56:1487-1493.

53. Mattei J, Achcar RD, Cano CH, et al. Gastrin-releasing peptide receptor expression in lung cancer. Arch Pathol Lab Med. 2014;138:98-104.

54. Carroll RE, Matkowskyj KA, Chakrabarti S, McDonald TJ, Benya RV. Aberrant expression of gastrin-releasing peptide and its receptor by well-differentiated colon cancers in humans. Am J Physiol. 1999;276:G655-G665.

55. Lango MN, Dyer KF, Lui VW, et al. Gastrin-releasing peptide receptor-mediated autocrine growth in squamous cell carcinoma of the head and neck. $J$ Natl Cancer Inst. 2002;94:375-383.
56. Baratto L, Jadvar H, Iagaru A. Prostate cancer theranostics targeting gastrinreleasing peptide receptors. Mol Imaging Biol. 2018;20:501-509.

57. Cescato R, Maina T, Nock B, et al. Bombesin receptor antagonists may be preferable to agonists for tumor targeting. J Nucl Med. 2008;49:318-326.

58. Roivainen A, Kahkönen E, Luoto P, et al. Plasma pharmacokinetics, whole-body distribution, metabolism, and radiation dosimetry of ${ }^{68} \mathrm{Ga}$ bombesin antagonist BAY 86-7548 in healthy men. J Nucl Med. 2013;54:867-872.

59. Zhang J, Niu G, Fan X, et al. PET Using a GRPR antagonist ${ }^{68} \mathrm{Ga}$-RM26 in healthy volunteers and prostate cancer patients. J Nucl Med. 2018;59:922-928.

60. Gnesin S, Cicone F, Mitsakis P, et al. First in-human radiation dosimetry of the gastrin-releasing peptide (GRP) receptor antagonist ${ }^{68} \mathrm{Ga}-\mathrm{NODAGA}-\mathrm{MJ} 9$. EJNMMI Res. 2018;8:108.

61. Kahkönen E, Jambor I, Kemppainen J, et al. In vivo imaging of prostate cancer using $\left[{ }^{68} \mathrm{Ga}\right]-$ labeled bombesin analog BAY86-7548. Clin Cancer Res. 2013;19:54345443.

62. Fassbender TF, Schiller F, Mix M, et al. Accuracy of $\left[{ }^{68} \mathrm{Ga}\right] \mathrm{Ga}-\mathrm{RM} 2-\mathrm{PET} / \mathrm{CT}$ for diagnosis of primary prostate cancer compared to histopathology. Nucl Med Biol. 2019;70:32-38.

63. Minamimoto R, Sonni I, Hancock S, et al. Prospective Evaluation of ${ }^{68}$ Ga-RM2 PET/MRI in patients with biochemical recurrence of prostate cancer and negative findings on conventional imaging. J Nucl Med. 2018;59:803-808.

64. Baratto L, Duan H, Harrison C, et al. Preliminary results of a prospective study of ${ }^{68} \mathrm{Ga}$-RM2 PET/MRI for detection of recurrent prostate cancer in patients with negative conventional imaging [abstract]. J Nucl Med. 2019;60(suppl):650.

65. Wieser G, Popp I, Christian Rischke H, et al. Diagnosis of recurrent prostate cancer with PET/CT imaging using the gastrin-releasing peptide receptor antagonist ${ }^{68} \mathrm{Ga}-\mathrm{RM} 2$ : preliminary results in patients with negative or inconclusive $\left[{ }^{18}\right.$ F $]$ fluoroethylcholine-PET/CT. Eur J Nucl Med Mol Imaging. 2017;44:14631472 .

66. Maina T, Bergsma H, Kulkarni HR, et al. Preclinical and first clinical experience with the gastrin-releasing peptide receptor-antagonist $\left[{ }^{68} \mathrm{Ga}\right] \mathrm{SB} 3$ and PET/CT. Eur J Nucl Med Mol Imaging. 2016;43:964-973.

67. Nock BA, Kaloudi A, Lymperis E, et al. Theranostic perspectives in prostate cancer with the gastrin-releasing peptide receptor antagonist NeoBOMB1: preclinical and first clinical results. J Nucl Med. 2017;58:75-80.

68. Wieser G, Mansi R, Grosu AL, et al. Positron emission tomography (PET) imaging of prostate cancer with a gastrin releasing peptide receptor antagonist: from mice to men. Theranostics. 2014;4:412-419.

69. Sah BR, Burger IA, Schibli R, et al. Dosimetry and first clinical evaluation of the new ${ }^{18} \mathrm{~F}$-radiolabeled bombesin analogue BAY 864367 in patients with prostate cancer. J Nucl Med. 2015;56:372-378.

70. Kurth J, Krause BJ, Schwarzenbock SM, Bergner C, Hakenberg OW, Heuschkel M. First-in-human dosimetry of gastrin-releasing peptide receptor antagonist $\left[{ }^{177} \mathrm{Lu}\right] \mathrm{Lu}-\mathrm{RM} 2$ : a radiopharmaceutical for the treatment of metastatic castration-resistant prostate cancer. Eur J Nucl Med Mol Imaging. 2020;47: 123-135.

71. Bresciani S, Garibaldi E, Cattari G, et al. Dose to organs at risk in the upper abdomen in patients treated with extended fields by helical tomotherapy: a dosimetric and clinical preliminary study. Radiat Oncol. 2013;8:247.

72. Delker A, Fendler WP, Kratochwil C, et al. Dosimetry for ${ }^{177}$ Lu-DKFZ-PSMA617: a new radiopharmaceutical for the treatment of metastatic prostate cancer. Eur J Nucl Med Mol Imaging. 2016;43:42-51.

73. Kabasakal L, AbuQbeitah M, Aygun A, et al. Pre-therapeutic dosimetry of normal organs and tissues of ${ }^{177}$ Lu-PSMA-617 prostate-specific membrane antigen (PSMA) inhibitor in patients with castration-resistant prostate cancer. Eur J Nucl Med Mol Imaging. 2015;42:1976-1983.

74. Sandström M, Garske-Roman U, Granberg D, et al. Individualized dosimetry of kidney and bone marrow in patients undergoing ${ }^{177} \mathrm{Lu}$-DOTA-octreotate treatment. J Nucl Med. 2013;54:33-41.

75. Park SY, Zacharias C, Harrison C, et al. Gallium 68 PSMA-11 PET/MR imaging in patients with intermediate- or high-risk prostate cancer. Radiology. 2018;288: 495-505.

76. Afshar-Oromieh A, Zechmann CM, Malcher A, et al. Comparison of PET imaging with a ${ }^{68} \mathrm{Ga}$-labelled PSMA ligand and ${ }^{18} \mathrm{~F}$-choline-based PET/CT for the diagnosis of recurrent prostate cancer. Eur J Nucl Med Mol Imaging. 2014;41:11-20.

77. Afshar-Oromieh A, Haberkorn U, Eder M, Eisenhut M, Zechmann CM. $\left[{ }^{68} \mathrm{Ga}\right]$ gallium-labelled PSMA ligand as superior PET tracer for the diagnosis of prostate cancer: comparison with ${ }^{18} \mathrm{~F}-\mathrm{FECH}$. Eur J Nucl Med Mol Imaging. 2012;39: 1085-1086.

78. Afshar-Oromieh A, Holland-Letz T, Giesel FL, et al. Diagnostic performance of ${ }^{68} \mathrm{Ga}-\mathrm{PSMA}-11$ (HBED-CC) PET/CT in patients with recurrent prostate cancer: evaluation in 1007 patients. Eur J Nucl Med Mol Imaging. 2017;44: 1258-1268. 
79. Jilg CA, Drendel V, Rischke HC, et al. Diagnostic accuracy of Ga-68-HBEDCC-PSMA-ligand-PET/CT before salvage lymph node dissection for recurrent prostate cancer. Theranostics. 2017;7:1770-1780.

80. Rauscher I, Maurer T, Beer AJ, et al. Value of ${ }^{68} \mathrm{Ga}$-PSMA HBED-CC PET for the assessment of lymph node metastases in prostate cancer patients with biochemical recurrence: comparison with histopathology after salvage lymphadenectomy. J Nucl Med. 2016;57:1713-1719.

81. Roach PJ, Francis R, Emmett L, et al. The impact of ${ }^{68} \mathrm{Ga}-\mathrm{PSMA}$ PET/CT on management intent in prostate cancer: results of an Australian prospective multicenter study. J Nucl Med. 2018;59:82-88.

82. Herlemann A, Wenter V, Kretschmer A, et al. ${ }^{68}$ Ga-PSMA positron emission tomography/computed tomography provides accurate staging of lymph node regions prior to lymph node dissection in patients with prostate cancer. Eur Urol. 2016;70:553-557.
83. Bailey J, Piert M. Performance of ${ }^{68} \mathrm{Ga}$-PSMA PET/CT for prostate cancer management at initial staging and time of biochemical recurrence. Curr Urol Rep. 2017;18:84.

84. Stoykow C, Erbes T, Maecke HR, et al. Gastrin-releasing peptide receptor imaging in breast cancer using the receptor antagonist ${ }^{68} \mathrm{Ga}-\mathrm{RM} 2$ and PET. Theranostics. 2016;6:1641-1650.

85. Zang J, Mao F, Wang H, et al. ${ }^{68} \mathrm{Ga}-N O T A-R M 26$ PET/CT in the evaluation of breast cancer: a pilot prospective study. Clin Nucl Med. 2018;43:663-669.

86. Abouzayed A, Yim CB, Mitran B, et al. Synthesis and preclinical evaluation of radio-iodinated GRPR/PSMA bispecific heterodimers for the theranostics application in prostate cancer. Pharmaceutics. 2019;11:E358.

87. Eder M, Schafer M, Bauder-Wust U, Haberkorn U, Eisenhut M, Kopka K. Preclinical evaluation of a bispecific low-molecular heterodimer targeting both PSMA and GRPR for improved PET imaging and therapy of prostate cancer. Prostate. 2014;74:659-668. 